\title{
AC 2010-1615: UNDERSTANDING THE DIFFERENCES BETWEEN FACULTY AND ADMINISTRATOR GOALS AND STUDENTS' EXPERIENCES WITH ETHICS EDUCATION
}

\section{Matthew Holsapple, University of Michigan}

Matthew A. Holsapple is a doctoral candidate at the Center for the Study of Higher and Postsecondary Education at U-M. His research interests include the impact of educational experiences on student moral development and personal and social responsibility, professional ethics education, college student outcomes assessment, and quasi-experimental research design in higher education. He is currently a member of the American Education Research Association, Association for the Study of Higher Education, and NASPA-Student Affairs Administrators in Higher Education.

\section{Donald Carpenter, Lawrence Technological University}

Donald Carpenter, Ph.D., P.E., LEED AP is an Associate Professor of Civil Engineering. He is actively involved in ASEE, is a Kern Fellow for Entrepreneurial Education, and serves as Director of Assessment for Lawrence Tech. His research interests involve academic integrity, assessment of student learning, and water resources.

\section{Janel Sutkus, Carnegie Mellon University}

Janel A. Sutkus, Ph.D., is Director of Institutional Research and Analysis at Carnegie Mellon University, where she is responsible for analysis and assessment of all administrative and academic functions. Her work focuses on student engagement, enrollment prediction, modeling responses to institutional financial aid, and developing an integrated model of student persistence within Carnegie Mellon's six undergraduate colleges. She is currently a member of ASEE, the Association for Institutional Research, and the Association for the Study of Higher Education.

\section{Cynthia Finelli, University of Michigan}

Cynthia Finelli, Ph.D., is Director of the Center for Research and Learning North at U-M. In addition, she actively pursues research in engineering education and assists other faculty in their scholarly projects. She also is past Chair of the Educational Research and Methods Division of ASEE and guest co-editor for a special issue of the International Journal of Engineering Education on applications of engineering education research.

\section{Kelley Walczak, University of Michigan}

Kelley Walczak is a doctoral student in the Center for the Study of Higher and Postsecondary Education at U-M. Her research interests include student development, campus culture, learning styles, and qualitative methodology. She is currently a member of the Association for the Study of Higher Education, American Educational Research Association, and ACPA-College Student Educators International.

\section{Trevor Harding, California Polytechnic State University}

Trevor Harding, Ph.D., is Professor and Chair of Materials Engineering at California Poly, where he teaches courses in engineering design from a materials perspective. His research focuses on educational outcomes associated with service learning and project-based learning with a particular emphasis on ethics education. He is also PI on several projects investigating the degradation of biomedical materials in physiological environments. Dr. Harding is Associate Editor of the journal Advances in Engineering Education, chair of the Materials Division of ASEE, and program chair of the Educational Research and Methods Division of ASEE. 


\title{
Understanding the Differences between Faculty and Administrator Goals and Students' Experiences with Ethics Education
}

\begin{abstract}
There is strong agreement about the need for effective ethics education in engineering academic programs, but students who graduate with a bachelor's degree in engineering continue to be unprepared to face the ethical dilemmas of professional engineering. This study uses qualitative data collected at 18 diverse institutions and employs the Transmission Model of Communication to examine ethics education. We investigate the ways that communication channels and noise contribute to discrepancies in the goals and perceptions of faculty and staff and the experiences of students in regards to curricular ethics education. We present data that shows that faculty and administrators consider a balance between the knowledge of ethics, ethical reasoning, and ethical behavior to be important, while students report experiencing ethics education that focuses almost solely on knowledge. The paper uses this discrepancy as an illustration to demonstrate the way the model can be used to identify factors that contribute to these differing perceptions. Our work provides support for the use of the model for understanding ethics education. Implications for educators are presented.
\end{abstract}

\section{Introduction}

The need for engineering programs to educate students to be ethical engineers is well documented. The National Academy of Engineering (NAE), in a report on the competencies necessary for the next generation of engineers, suggests that future engineers will need to "possess a working framework upon which high ethical standards and a strong sense of professionalism can be developed," and the Accreditation Board of Engineering and Technology (ABET) has stressed the importance of colleges and universities providing students with effective ethics engineering education ${ }^{2}$.

Despite these calls, ethics education efforts have differing levels of success. In another report, NAE expressed concern that students are not being well-educated to understand the "social and ethical implications" of their technical skills ${ }^{3}$, and empirical evidence suggests that some of the practices used in engineering ethics education, including case studies and embedded ethics modules in other courses may have mixed results ${ }^{4,5,6}$. Further, researchers have consistently demonstrated that engineering students have high rates of cheating on academic work ${ }^{7}$ and are among the mostly likely students on campus to cheat ${ }^{8}$; this student cheating has been correlated with unethical behavior in a workplace environment ${ }^{9}$. So although the field of engineering is in agreement about the importance of ethics education, current methods of engineering education may not be adequate to prepare students with needed ethical competencies. 
In this paper, we explore one potential way of examining the gap between the recognized need for results of professional engineering ethics education by investigating two research questions:

1. In what ways do the faculty and administrator goals for and perceptions of ethics education at their institutions differ from the experience of the institutions' students?

2. How do the communication channels and noise in the communication process of ethics education affect those differences?

\section{Conceptual Framework}

This paper is built on the conceptual framework of two distinct models: a model of engineering ethics education and Shannon and Weaver's Transmission Model of Communication. The former model was used to inform the study's design and data collection, while the latter informed data analysis and interpretation.

In this paper, data collected as part of an ongoing study of ethics education in undergraduate engineering programs are utilized. The conceptual framework (Figure 1) used in this larger investigation draws upon Rest's Four Component Model of Morality ${ }^{10,11}$; prior research supports this as appropriate for the study of ethics education and development ${ }^{12}$. With this theories as a

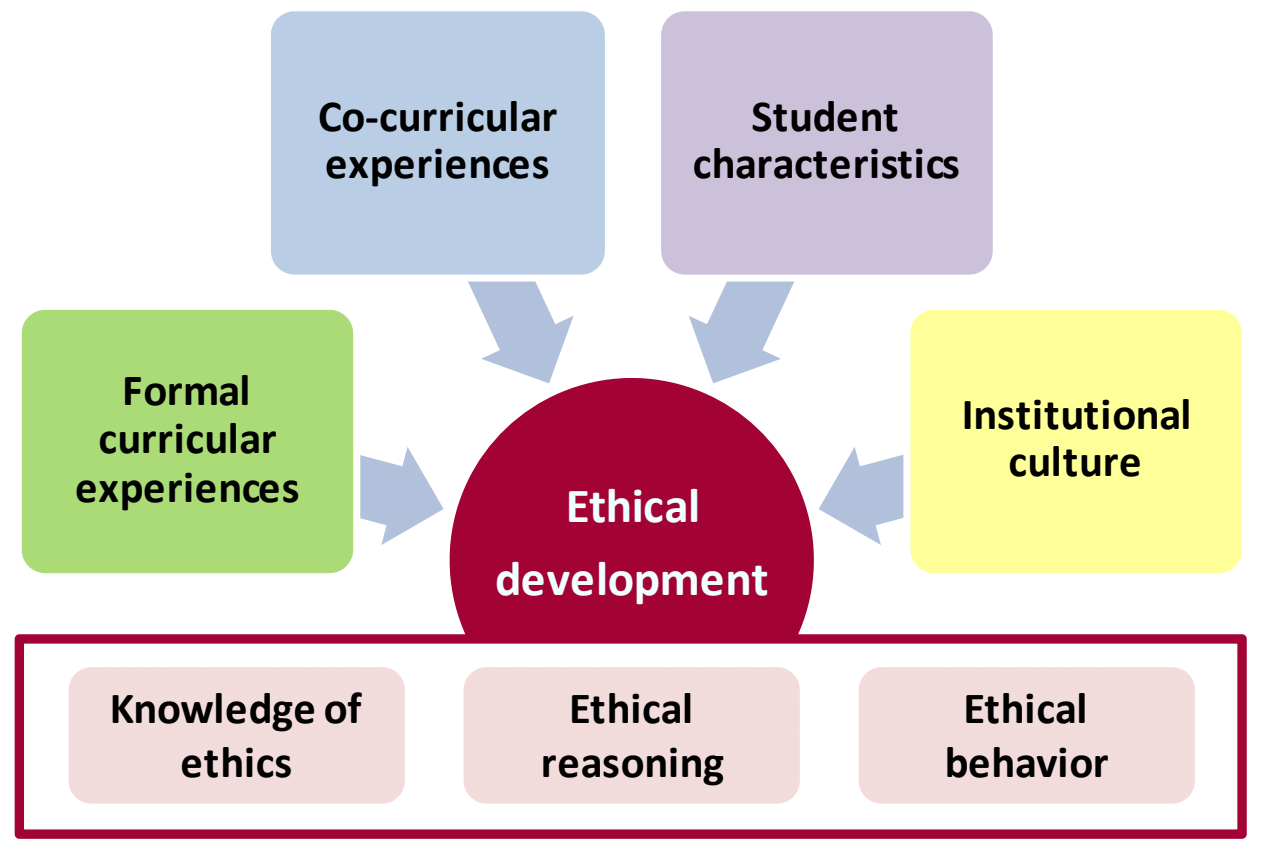

Figure 1. Holistic model of engineering ethics education and ethical development.

guide, the model in Figure 1 affords a holistic view of ethical development and includes several input variables (curricular experiences, co-curricular experiences, student characteristics, and campus culture) and measurable output constructs (knowledge of ethics, ethical reasoning, and ethical behavior). In the model, knowledge of ethics refers to a student's understanding of 
professional engineering codes of ethics and other rules governing ethical behavior; ethical reasoning refers to a students' ability to apply reason when identifying ethical options to professional engineering ethical dilemmas, and ethical behavior refers to the ability of the student to engage in behaviors consistent with his or her reasoned ethical decision ${ }^{13}$.

Higher education research has demonstrated that students and faculty often have discrepant perceptions of the content and effectiveness of instruction. For example, there have been shown to be large differences between students and faculty perceptions of teaching and instructor performance $^{14,15,16}$, students' received level of feedback ${ }^{17}$, and the value and effectiveness of learning assessments ${ }^{18}$. Here, we use the Transmission Model of Communication to examine discrepancies in the context of ethics education, specifically between the goals and perceptions of engineering faculty and administrators and students' experiences, as a way to better understand the gap between the field's goals and the lack of ethical preparation for students and beginning professional engineers.

The Transmission Model of Communication ${ }^{19}$ (also known as the Mathematical Model of Communication) was first published in 1949 as a framework for the efficiency of telephone and radio communication ${ }^{20}$, but the model has been used extensively in the years since as a framework to understand any type of communication between a sender and a receiver ${ }^{20,21}$, such as the communication between an instructor and a student. In the model, communication is represented as a linear process in which a message is transmitted between a sender and a receiver, with the receiver then providing feedback of his or her understanding of the message (See Figure 2). For example, an instructor (sender) gives a lecture about ethical failings in the Challenger space shuttle explosion (message) to students in her class (receiver). Or, the model could be used to describe communication on a larger scale, with an engineering program as an organization (sender) sending consistent messages about professional ethics to the student body (receivers).

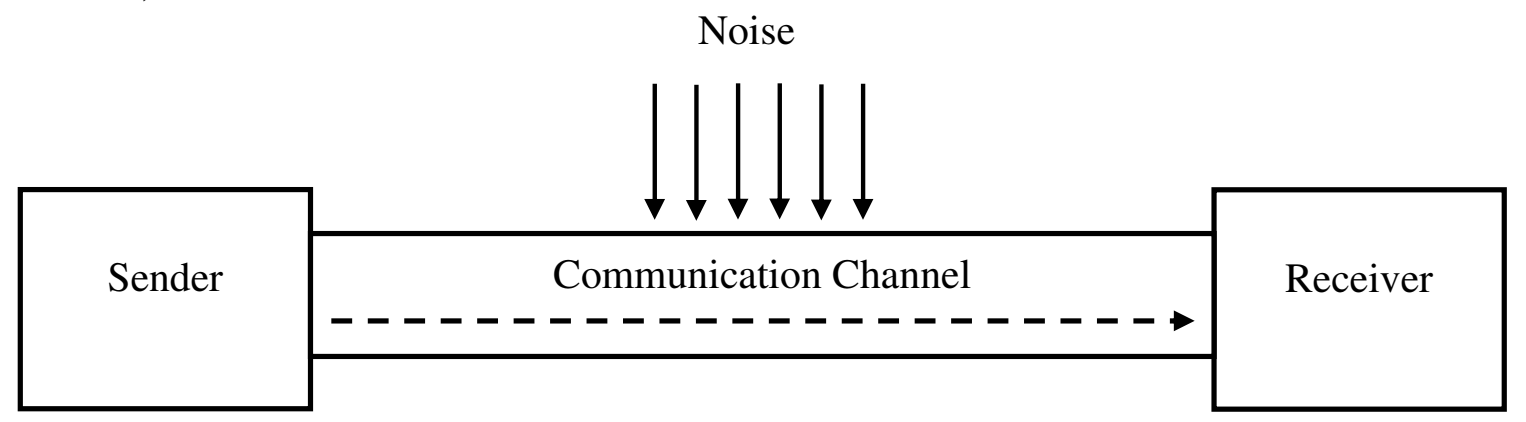

Figure 2. Transmission Model of Communication (adapted from Weaver and Shannon ${ }^{21}$ ).

In either the small- or large-scale applications, two aspects of the communication process can lead to differing interpretations of the message sent to the receiver: communication channels and noise. Communication channels refer to the method through which the sender delivers the message to the receiver. In the example of the instructor lecture about the Challenger disaster, the communication channel is that face-to-face lecture; in the larger-scale example, the communication channels could include any number of communication methods, such as lectures, one-on-one conversations, or the choice of content for required courses. In the model, noise 
refers to any type of interference - internal or external - that affects the message as it travels along the communication channel and is interpreted by the receiver. In the case of the instructor lecturing on the Challenger, for example, noise could include other activities happening in the classroom, like students talking or reading a newspaper; students' preconceived ideas about the disaster; their interest or lack of interest in the topic; or other lectures the instructor has previously given on similar topics. Anything related to the sender, communication channel, or receiver can serve as noise and interfere with or distort the message the instructor is attempting to send, leading to discrepancies between this intention and the way that students perceive the message. Despite being a seminal theory in communication studies and having been applied throughout the social sciences, the Transmission Model of Communication has not been widely applied to the college classroom. In this paper, we propose the model as a way to examine curricular engineering ethics education.

\section{Methods and Data}

Over the course of three years, we conducted focus groups with engineering faculty and students and personal interviews with senior-level academic and student affairs administrators at the engineering schools or departments at 18 colleges and universities. These institutions were chosen to represent the wide range of institutions that provide engineering education to the largest number of students throughout the country. Partner institutions were selected based on large enrollment in traditional engineering disciplines, diversity of student populations, geographic location, and to represent a wide range of Carnegie Foundation ${ }^{22}$ classification (very high research, high research, master's, baccalaureate and specialty institutions).

After obtaining Institutional Review Board approval from each of these institutions, we collected data from three distinct populations: undergraduate engineering students, engineering faculty, and senior-level administrators; administrators represented both academic and student affairs administrators. These four populations were chosen based on the differing perspectives that each would have on students' ethical development, and the different aspects of that development to which those participants would have direct experience. Students were selected for the study via random selection, and faculty and senior administrators were recruited based on their familiarity with their institutions' ethics education practices and students' ethical development.

This selection yielded a sample of 123 students and 110 faculty, who participated in a total of 36 student- or faculty-specific focus groups - one for each group at each of the 18 partner institutions. Personal interviews were also conducted with a total of 37 senior administrators. Protocols for the focus groups and interviews included two parts: in each, participants discussed elements of the institutional culture that they saw as affecting students' ethical development, and participants were either asked to discuss the ways that ethics was incorporated into the students' experiences or the ways that students identified and approached ethical dilemmas. The characteristics of student participants roughly matches the demographic characteristics of undergraduate engineering students nationwide ${ }^{23}$, except our sample includes a larger proportion of women and a smaller proportion of international students. See Table 1 for additional information about the student and faculty samples. Because of the small number of administrators interviewed on each campus, potentially identifiable demographic characteristics were not collected for these participants in order to protect their confidentiality. 
Table 1. Demographic characteristics of participants in student and faculty focus groups.

\begin{tabular}{|l|c|c|}
\cline { 2 - 3 } \multicolumn{1}{c|}{} & $\begin{array}{c}\text { Students } \\
(n=123)\end{array}$ & $\begin{array}{c}\text { Faculty } \\
(n=110)\end{array}$ \\
\hline Male & 84 & 92 \\
\hline Female & 39 & 18 \\
\hline American Indian or Alaskan Native & 1 & 2 \\
\hline Asian & 11 & 11 \\
\hline Black or African America & 17 & 2 \\
\hline Native Hawaiian or Other Pacific Islander & 1 & 0 \\
\hline White & 93 & 100 \\
\hline Hispanic & 5 & 5 \\
\hline Freshman & 26 & - \\
\hline Sophomore & 24 & - \\
\hline Junior & 25 & - \\
\hline Senior & 48 & - \\
\hline Tenured & - & 62 \\
\hline Non-Tenured, but Tenure Track & - & 22 \\
\hline Not on Tenure Track & - & 26 \\
\hline Very High Research & 30 & 32 \\
\hline High Research & 16 & 29 \\
\hline Master's & 46 & 26 \\
\hline Baccalaureate and Specialty & 31 & 23 \\
\hline
\end{tabular}

Note. Some participants did not provide responses to all demographic questions, so response totals may not match.

\section{Analysis}

Transcripts from each focus group and interview were analyzed and coded using a comparative case study approach to identify discrepancies between the perceptions of students and faculty and administrators and ways that communication channels and noise contributed to those discrepancies. To answer the first research question (In what ways do the faculty and administrator goals for and perceptions of ethics education at their institutions differ from the experience of the institutions' students?), on all transcripts data referring to curricular ethics education was coded as referring to its need, implementation, or efficacy. Then, comparisons were made for each campus to identify campus-specific discrepancies between the way that faculty and administrators and students discussed these aspects of ethics education. When differences emerged, those that showed discrepancies between the goals and perceptions of faculty and administrators of ethics education in practice and the experiences of students at the same institution were noted. Finally, comparisons of institutional themes were made to identify themes of discrepancies that applied across the sample of institutions.

To answer the second research question (How do the communication channels and noise in the communication process of ethics education affect those differences?), the transcripts were reanalyzed. This time, the discussions of the need, implementation, and efficacy of ethics 
education were coded for ways that communication channels and noise contributed to the discrepancies. Based on the discussion of the Transmission Model of Communication, communication channels were defined as any method through which messages about ethics were transmitted from faculty and administrators to students and noise was defined as any aspect of the student curricular experience that interferes with or contradicts the messages of ethics education that faculty and administrators wish to transmit to students. Then, data that had been coded as referring to one of these aspects of the communication was recoded using an opencoding process ${ }^{26}$, so that themes emerged from the data without predetermination. Those emergent themes were consolidated within each institution, and then institutional comparisons were made to determine the extent to which they applied across institutions. For both research questions, the themes discussed in this paper were chosen for two reasons: their consistency across institutions and their power to illustrate the use of the Transmission Model of Communication in examining ethics education.

\section{Results}

Results from the analyses indicate that discrepancies do exist between the way that students, faculty and administrators perceive the implementation, efficacy, and need for including ethics in the engineering curricula at the institutions. Additionally, these results suggest that the discrepancies are at least partially the result of the communication channels used in ethics education and noise that interferes with that education. These results support the use of the Transmission Model of Communication as one way of considering the ways that the goals and perceptions of faculty and administrators differ from the experiences of students in regards to ethics education. To illustrate this support, we will discuss one discrepancy that arose consistently across institutions and aspects of the communication channels and noise that contributed to this discrepancy.

\section{$\underline{\text { Research Question } 1}$}

This study's first research question (In what ways do the faculty and administrator goals for and perceptions of ethics education at their institutions differ from the experience of the institutions' students) investigates the ways that faculty and administrators' goals for and perceptions of ethics education at their institutions differ from the experience of the institutions' students. Results from this study support the proposition that these discrepancies do exist. In one common manifestation of these discrepancies, students did not see the balance between the knowledge of ethics, ethical reasoning, and ethical behavior in their ethics education that faculty and administrators described.

Faculty and administrators described a need for ethics education to move beyond the knowledge of ethics and provide substantive education on ethical reasoning and ethical behavior; they frequently described the curricular ethics education efforts at their institution as striking a balance between these goals. Curricular ethics education, they said, included not only understanding professional codes of ethics and legal issues for engineers, but also helping students to recognize and make sense of ethical dilemmas through their own ethical and moral standards. However, students at these same institutions reported that curricular ethics education mostly focused on the knowledge of ethics. In some cases, students expressed frustration that 
their ethics education had not gone beyond the knowledge of ethics to include ethical reasoning and ethical behavior, which they saw as valuable to their professional preparation as ethical engineers.

During faculty focus groups and administrator interviews, members of both groups stated that professional ethics education in engineering courses should focus on preparing students to wrestle with ethical dilemmas and make decisions that adhere to both the established ethics codes and conventions of the profession as well as their own sense of what is ethical and moral. Faculty and administrator participants acknowledge the importance of students learning the professional codes of ethics, but they also emphasize that students should see ethical dilemmas and choices as complex and "grey," rather than dualistic questions of right versus wrong (i.e. "black and white").

One faculty member, for example, stated that students do not respond to simply being told what is ethical and what is not; effective ethics instruction instead should focus on thinking through the long-term effects of decisions and understanding why some choices are ethical while others are not. The faculty member said:

Our students are very good at picking up on empty rhetoric ... If you can explain to the students why - for example, you don't want to have landfills, you know, loaded with toxic waste - why you need to take that into account in your design, they'll listen and they'll understand. But just telling people, 'Be ethical because I say so,' isn't going to go anywhere.

For this faculty member, the emphasis should not be on telling students what is ethical and what is not, but instead on educating students to understand the background and implications of ethical dilemmas to prepare them to make ethical choices.

A faculty member at another campus discussed that although students need to understand the professional codes of ethics and how engineering works within a legal framework, they also need to be taught to understand the impact their decisions have on the public. Ethics education should prepare students to move beyond code-based and legal perspective to a more holistic approach that integrates the needs of the public and the student's own ideas about ethics and morality. This faculty member stated:

The problem that I see students facing is that we have such a litigious society and many things that are legally correct but ethically wrong from a professional point of view. And this has to be brought out that, you need to do what's right for the public, not necessarily what the law might say. So they have all these dilemmas that they run into and to lead them through it and let them develop their own mentality that this is, you have to be conscience of your responsibility as a professional that you are there to protect the health and safety of the people in whatever you do.

In addition to believing that this more holistic approach incorporates ethical reasoning and behavior with the knowledge of ethics is important to better prepare students, faculty also talked about the appeal those topics had for students. Although students were often not engaged when 
courses covered aspects of knowledge of ethics related to following established rules, they were much more interested when the course incorporated more complex and ethically ambivalent issues that helped develop their ethical reasoning. For example, at one institution, faculty talked about their efforts to incorporate these types of issues alongside learning the engineering codes of ethics and academic integrity issues. One faculty member said:

I do notice that the students get a lot more engaged when we start talking about ethical issues, not just in, you know, the traditional engineering sense, like I'm not going to copy off of somebody or I'm not going to steal somebody's ideas and, you know, steal, you know, tens of millions of dollars of ideas and take them to China or something like that. But when you start talking about real people's lives and the difference that you can make in them, they do get really engaged in that.

For another faculty member, an approach to ethics education that focuses on reasoning rather than simply memorizing ethical knowledge is an extension to the teaching of engineering in general. As a field that relies heavily on problem-solving and analytical thought, engineering programs help students to take that same approach to ethical dilemmas:

What we can do in engineering is teach a thought process. Rather than, "How do we get the answer?" have the students ask the questions, "How is this going to impact others? What is the follow-on project? What's the impact on nature?" and so on. Some of the courses...we can tell them there are different ways of looking at it; you'll get different answers depending on the question you ask.

Many faculty members discussed the need to balance the knowledge of ethics in professional engineering ethics education with the inclusion of ethical reasoning and ethical behavior. Students at these campuses, though, described professional ethics education in engineering classes as focusing primarily on adherence to codes of professional ethics and avoiding the punishments and negative personal consequences that can arise from unethical decisions and actions. In some cases, students stated they desired the kind of ethics education that the faculty and administrators described, but did not perceive they were receiving it in their engineering courses.

Some more advanced students reported they received little ethics education during their time at their institutions, regardless of the focus. Therefore, not only did they not perceive that they were receiving education about ethical reasoning and ethical behavior, but also they did not perceive even education about the knowledge of ethics. A fifth-year student, for example, could remember learning about professional responsibilities only once since beginning the institution's engineering program:

I've been here for five years and I've only had one class actually mention or teach a twoweek session on ethics and that was in my first year, freshmen year. I haven't had any class other than that, say, 'okay let's sit down and talk about ethics and what that involves.' 
Students at other institutions echoed this concern about a general lack of ethics education. Another student majoring in bioengineering said:

I think it's a little disconcerting 'cause out of...I think, personally, out of all of these engineering majors, that the bioengineering is under the most scrutiny as far as ethics goes because there are far too many [unethical] options for us to pick and [the school] does a lot to prepare us for our future careers but, as far as the ethics goes, I haven't seen much support or attempt at guidance.

When students did acknowledge receiving larger amounts of professional ethics education in their engineering courses, they reported frustration that this education emphasized the knowledge of ethics instead of incorporating a larger focus on ethical reasoning and behavior. For example, students at one institution expressed concerns that their ethics education was almost solely focused on academic integrity and being cautioned not to cheat on coursework. These students wanted their ethics education to include discussion of complex ethical dilemmas that engineers face. Another bioengineering student said:

I think bioengineering, like the ethics kinda go beyond just cheating or faking data. I mean, you have to deal with animal testing or, you know, stem cells. Like, is that ethical?

Many other students agreed that they wished these types of ethical issues were focused on helping students consider the reasons for and implications of ethical dilemmas and choices. Even in discussions of academic integrity, some students saw opportunities for faculty to discuss more about ethical reasoning. One student, for example, discussed a faculty member who encouraged students to purchase textbooks by "just going online and get the $\$ 30$ one that's made for India that they ship from overseas" rather than paying for the more expensive version of the textbook that was printed for students in the United States. The student saw this not only as encouraging unethical behavior, but also missing an opportunity to discuss factors that lead to the different prices and inform the ethical decision. The student said:

Ifeel like that's a critical thing where this professor is you know, endorsing that sort of behavior that's obviously not ethical and yes, a lot of kids do buy the soft cover versions, which are not intended for U.S. use. However I don't think it's ethical, you know, the teacher shouldn't say, you should buy this one because it's cheaper, or encourage that practice. He should have a discussion and say, these are cheaper, here's why they're cheaper.

In general, students saw that the ethical dilemmas that confront engineers and the decisions that they make in response to those dilemmas affect not just the engineer making the decision but also communities and society as a whole. They wished that ethics education would focus more on the ethical reasoning needed to think about and balance those potential impacts. One student said:

I think the university could do a lot to promote ethics and they already do a lot but I think they could kinda broaden what they do ... If, I think, the university concentrates less on promoting ethics in specific examples like cheating on a test, and more in a broad way 
like, exposing students to more things, increasing awareness of something important to society you know, then you can promote ethics.

A student in the same focus group agreed, saying:

[Professional ethics] is really not addressed very much, and so it's easy for engineers to just be in like a little bubble - 'I'm doing this formula, solving this equation' - but they don't really talk about engineers' influence on society and, like, corporate social responsibility and things like that, which are important for all engineers.

Across the institutions there were discrepancies about the emphasis placed on the three components of professional ethics education in engineering courses. Faculty and administrators consistently talked about the importance of not only educating students for the knowledge of ethics, but also for ethical reasoning and ethical behavior, describing the curricular ethics instruction in their programs as balancing these components. Students, however, stated that their ethics education had focused almost exclusively on knowledge of ethics and expressed frustration at the lack of emphasis on ethical reasoning and behavior and the more complex issues confronted by professional engineers. This is one example of a discrepancy in perception between educators and students that supports the supposition in this paper that one reason for less successful ethics outcomes may be these different perceptions about what students are actually being taught.

\section{$\underline{\text { Research Question } 2}$}

For the second research question in this study (How do the communication channels and noise in the communication process of ethics education affect those differences?), we asked how communication channels and noise contributed to the faculty, administrator, and student discrepancies; results suggest that both aspects of the communication process do indeed contribute. In this section, we discuss three emergent themes from the data.

\section{Communication Channels}

The impact of communication channels on ethics education was often recognized by faculty and administrators, who directly discussed these issues during their focus groups and interviews. This suggests that they recognize at least some of the negative impact that communication channels are having on their efforts to educate students in engineering ethics, and we discuss one theme that supports this.

Theme 1: The lack of clear and consistent approaches to ethics education within engineering schools and departments - i.e., inconsistent communication channels.

In focus groups and interviews, faculty and administrators acknowledged concerns about the lack of consistent and organized ethics education approaches and messages within their engineering schools and departments. Despite being frequently discussed and viewed as important, ethics education is not purposefully integrated into the curriculum to the extent that many wish that it was. In many of these cases, faculty and administrators stated that although there was a strong 
desire within their schools and departments to emphasize ethics in their curricula, that desire is often not translated into a purposefully designed department- or school-wide approach. For example, one faculty member described a departmental state that encapsulated this issue in the communication channels between faculty and students:

From a university, college, and departmental level there's a lot of discussion about ethics, and I think every body's on board. It's an important topic, but the approach to the subject as best as I can see is very non-strategic. If it's truly important you would have a strategy to it.

A faculty member at another institution said that while faculty and administrators agree on the importance of ethics education, the only place there is an organized approach to teaching ethics is in the first-year introduction to engineering courses. Beyond those courses, the topic is left to individual departments and faculty:

Within the college itself, [ethics education] has taken up a significant amount of discussion in chairs meetings and, within our faculty itself. It has taken up a significant amount of discussion, and so the discussion is there. How much things show up in terms of student opportunities, in terms of curriculum, is probably still managed at the program level. I don't know that ... other than our freshman courses, I don't know any other places where there's really a college approach right now, although there's a lot of college discussion.

At one institution, the senior academic administrator who we interviewed discussed problems with taking full advantage of the communications channels at the engineering program's disposal to teach ethics. At the institution, the administrator said, there was a desire to institute a full course on professional ethics, in part to prepare students for the Fundamentals of Engineering exam. However, there was not enough space in the curriculum to add the class, meaning that despite that desire and belief in the importance of ethics education, ethics could only be added an existing class, and then addressed whenever possible across the curriculum. The administrator said:

I wanted to have a full course in ethics, but engineering curricula are kind of crowded with things, so we have an Introduction to Engineering and about half of that course is devoted to trying to get them ethically trained ... We could have a course every year in it - and I don't think that would be enough — but the barrier would be we just don't have that kind of space to formally do that in the curriculum. The technical material has to be presented and we are constrained to the number of hours we can require them to take.

In these cases and others, despite an organizational desire among the faculty and administrators to teach ethics in a consistent and organized way across the curriculum, that desire has not become a reality. The communication channels most frequently used to teach ethics to students are freshman year introduction to ethics and senior-level design practicum classes, with other communication channels for ethics being haphazard and idiosyncratic to the students' specific courses and experiences. According to faculty and administrators, that lack of additional purposeful communication at the college and department level contributes to the discrepancies 
between the perceptions of faculty, administrators, and students discussed in the previous section.

Noise

In addition to communication channels used for ethics education causing discrepancies in perception, there is also noise that interferes with the engineering ethics education message as it travels between faculty and students in the classroom. In focus groups and interviews, all three groups discussed the role that the amount of stress and required academic work play as noise interfering with the ethics education messages for students, particularly when students find it difficult to succeed without cheating in classes. Participants also discussed the focus on academic integrity issues and the use of punishment and other negative personal consequences to deter unethical behavior. These themes provide examples of the ways that aspects of the students' experiences (noise) interfere with the messages about ethics education that faculty and staff report wanting to impart, contributing to the discrepancies discussed earlier in the paper.

Theme 2: An institutional environment of academic pressure and stress leads students to unethical behaviors.

Many of the ethics education messages directed at students in engineering courses take the form of academic ethics rather than professional ethics (this is discussed more in the next section). While faculty believe they are teaching students to be more ethical through these messages about academic integrity, the environment that leads some students to disregard these messages serve as noise competing with that message.

One faculty member discussed that despite the reliance on academic ethics in teaching ethics in engineering programs, students do not see their unethical behavior in academics as related to future professional behavior. Instead, the professor said, students see the academic dishonesty as something that they have to do in order to meet the demands of their academic programs:

There's a big divide between the professional ethics and the academic ethics. There's no question of academic ethics to them. It's what has to be done today to get today's assignments done and to write something tonight to turn into Humanities tomorrow. That's not about ethics [in the students' minds], that's about what [they] need to do .... I mean, they might be heading for a great ethical professional conduct career, but right now it's not inconsistent for them to cheat like mad.

In one focus group, students discussed the messages they had received from faculty specifically encouraging them to cheat on academic work if it would make the difference between failing and passing a class. One student said:

I heard a professor say in the class one day, a type of study session, and these are his exact words: 'It's better to cheat than repeat. Just don't get caught.' 
At another institution, a faculty member admitted that he had discouraged students from spending time on volunteer or service activities - activities that demonstrate positive ethical behavior - because of how busy the students are with coursework.

I guess volunteer work is important but it's not what I would emphasize with our students. In fact, I discourage them if they're spending too much time volunteering, saying, 'Don't do that. You're taking time away from your studies.'

In both of these cases, faculty members were either encouraging unethical behavior or discouraging ethical behavior in response to amount of required coursework students faced. An administrator at another institution further discussed how the stress of coursework leads students to cheat on academic work. This administrator said students often feel forced into cheating by the pressures of the curriculum, feeling like they have little choice if they want to succeed:

And the kind of student who [cheats], I think, does it almost against their will, almost involuntary. We work them so hard here that they get very tired and it becomes increasingly an option just this once, just this one time I'm going to pull a paper from the internet. And they almost don't mean to do it. They're almost forced into it by the curriculum, and it tends to be transfer students who aren't used to us yet.

This type of unethical behavior as a response to institutional academic factors does not only manifest itself in cheating on academic work, but also other unethical behaviors. One student, for example, talked about the high proportion of students who pirate design software that they need to use to complete coursework:

I think that almost all students here have a copy of the software they need for their class work at home. You could probably get away with just doing the work at school labs and so on, but I'll make an example: One of our freshman requirements is an AutoCAD class, and I believe all the students in my dorm at least had AutoCAD on their home laptops. I don't believe most of them are legal. It's just that you are doing long hours and so on, the labs are open only so late, and it's not often convenient for us to work here, so it's just more convenient to work at home and if you need to work on a project than you need that software at home.

So while faculty are teaching ethics in engineering coursework - often through messages about academic ethics - the amount of work required in the students' courses and the stress that arises from that work becomes noise competing with those messages of ethics education. That stress and work level often lead students toward unethical behavior - such as cheating - thereby serving as noise for the message of ethics education and contributing to the discrepancies between faculty, administrator, and student perceptions.

Theme 3: A focus on academic integrity and punishment as an academic cheating deterrent detracts from more complex and treatment of professional ethics education.

A second theme emerged to illustrate another way that noise can contribute to discrepancies between students, faculty, and administrators in regards to ethical education - an over-reliance 
on academic ethics education and punishment as a deterrent of unethical behavior. As discussed earlier, faculty and administrators hold a consistent belief that ethics education should move beyond simplistic messages of just following codes of ethics and legal restrictions to a more nuanced approach where students are analyze complex ethical and moral situations they will encounter as professionals. However, these faculty and administrators - as well as students at their institutions - discuss the teaching of academic ethics as black and white, in which students are taught to follow rules in order to avoid consequences. Since this is one of the major forms of ethics instruction that students receive, particularly during their first years, this focus on academic integrity and not cheating in curricular ethics instruction acts as noise because it crowds out messages about more nuanced ethical decision-making in the professional context.

One fifth-year student stated that ethics instruction during the first year had incorporated professional ethics issues, but beyond that almost all attention paid to ethics was to caution students not engage in specific types of academic cheating. The student said:

As a fifth-year, beyond the freshman engineering courses that all [this institution's] engineers have to take, I really had very little ethics, specifically ethical reasoning training or experience in these situations just developing the ability to recognize an ethical problem. Beyond that first class, the only kind of ethics that we encounter is academic ethics, you know integrity and not copying other people's work, plagiarism, and other than that I had no experience.

Faculty at the same institution echoed students perceptions of the focus on academic ethics compared to broader discussions of professional ethics. These faculty discussed that the messages sent to students about academic ethics emphasize the importance of ethical behavior because of the consequences to the students if they are caught cheating, rather than discussing other implications of unethical academic behavior. For example, one faculty member said:

The institution says that we're watching you and there are ways we're going to catch you. It's completely backwards from an academic environment.

Another faculty member echoed that perspective:

I think that the message that's coming across is we know you're all cheating, and here's how we can catch you, or we're expecting you to cheat. And, you know, that's not what we want to send.

A faculty member at another institution had similar concerns that messages about academic ethics were much more focused on punishment and consequences than critical thinking about ethical behavior. This faculty member reported struggling with the way to present academic ethics information in class so that the noise of punishment and consequences was limited, saying:

My syllabus has a really lengthy discussion on the consequences of academic dishonesty and the importance of it. And basically the university has a policy that you can refer to and talk about the consequences and [how] one bad decision can have a long-lasting impact. But I'm still struggling to find a better way, rather than threatening them, to get 
them to appreciate the importance [of ethical behavior] but I just can't come up with a better solution other than just sort of describing the worst case scenario and sort of motivating them to be honest.

Despite the widespread belief that ethics education should move beyond educating students to follow rules and avoid punishment, students, faculty, and administrators describe an approach to ethics education that often focuses primarily on academic ethics rather than professional ethics. Moreover, the common approach to academic ethics described is one that focuses on punishment and negative consequences to students if they do not follow a set of rules about academic integrity. While educating students to avoid cheating in academic coursework is important, this focus creates noise that contributes to the discrepancies described earlier in this paper between faculty and administrators' desire to educate students to appreciate the nuanced and complex ethical dilemmas that face professional engineers and students' perception that their ethics education focuses following rules and avoiding negative personal consequences.

\section{Discussion and Implications}

In this paper, we use data from faculty and student focus groups and administrator interviews from a representative sample of 18 engineering programs to examine the discrepancies between the perceptions of educators and students in regards to curricular ethics education. Further, we use the Transmission Model of Communication as a framework to understand how communication channels and noise contribute to these discrepancies. Results of this study support the hypothesis that significant differences do exist between the perceptions of faculty and administrators and students in regards to ethics education. For example, we report that faculty and administrators express support for an approach to ethics education that emphasizes critical thinking and incorporating personal ethical and moral perspectives with legal requirements and professional codes of ethics, but students report experiences in curricular ethics education that focus primarily on following rules and behaving ethically in order to avoid punishment and negative consequences. The results suggest that communication channels and noise contribute to the development of these discrepancies between the perceptions of faculty, administrators, and students. Specifically, the lack of coordinated and purposeful approach to ethics education at the college and department levels; an academic culture that leads students toward unethical behavior; and a focus on the negative personal consequences of academic cheating are shown to contribute to this discrepancy.

The results of this study suggest multiple implications for engineering educators. Given the importance of ethics education to the field of professional engineering and the accreditation of academic engineering programs, understanding how students perceive their experiences is an important step in assessing the effectiveness of ethics education in academic programs. In the context of the results of this study, it is possible - even likely - that faculty members' and administrators' ideas about their programs' curricular ethics instruction do not match the experiences of their students. It would be virtually impossible to understand the effectiveness of these curricular efforts without knowing how students perceive their experiences.

Further, understanding how discrepancies between the perceptions of faculty, administrators, and students affect ethics education on a specific campus can be invaluable to understanding ways to 
ameliorate these discrepancies. For example, the result of this study suggest three specific aspects of the communication process that contribute to these discrepancies, providing three avenues educators can follow to begin decreasing these discrepancies. In any engineering program, these aspects of the communication process will contribute to these discrepancies in different ways, depending on the student and institutional culture, the curriculum in place, the methods used by different educators, organization factors, and other differences. Expanding the discussions and consideration of ethics education to include these aspects of the communication process, will also allow educators to better tailor their approaches to be effective in their specific institutional contexts.

Finally, it is likely that similar types of discrepancies exist in other types of instruction (besides ethics education), particularly in non-technical areas in which outcomes have traditionally been more difficult to assess. In these areas of engineering education - for example, teamwork, leadership, or communication skills - a careful examination of the perceptions of students about the messages they are receiving and how these perceptions do or do not match those of faculty and administrators can provide an important foundation to the assessment of the success of curricular efforts in these areas. Beyond that, when discrepancies are found, the Transmission Model of Communication can provide one framework to understand what contributes to these discrepancies. It is unlikely that the same communication channels and noise affect other types of education, or that they affect other types of education in the same ways. However, this study provides evidence that these aspects of communication can contribute to the development of discrepancies and lead to less effective education. Examining the effects of these aspects of communication in other areas will provide a better understanding to the reasons that curricular education may be less effective and changes that can be made to make it more effective. This information can help educators design courses and curricula addressing these outcomes in ways that lessen the discrepancies between the goals and perceptions of faculty and administrators and the experiences of students.

\section{Acknowledgement}

This work was supported in part by grants from the National Science Foundation (EEC\# 0647460, 0647532, and 0647929). The views expressed represent those of the authors and not necessarily those of the National Science Foundation.

\section{Bibliography}

1. National Academy of Engineering (2004). The engineer of 2020: Visions of engineering in the new century. Washington, DC: National Academy Press.

2. Engineering Accreditation Commission (2007). Criteria for accrediting engineering programs: Effective for evaluations during the 2008-2009 accreditation cycle. Retrieved January, 23, 2009, from Accreditation Board for Engineering and Technology website: http://www.abet.org/forms.shtml\#For_Engineering_Programs_Only

3. National Academy of Engineering (2003). Emerging technologies and ethical issues in engineering. Washington, DC: National Academy Press.

4. Bebeau, M. J. (2002). The Defining Issues Test and the Four Component Model: Contributions to professional education. Journal of Moral Education, 31(3), 271-295. 
5. Bebeau, M. J., \& Thoma, S. J. (1999). "Intermediate" concepts and the connection to moral education. Educational Psychological Review, 11(4), 343-360.

6. Etter, B.K., Harding, T.S., Finelli, C.J., \& Carpenter, D.D. (2004). The role of moral philosophy in promoting academic integrity among engineering students. Proceedings of the 34th Frontiers in Education Conference, Savannah, GA. (IEEE Catalog Number 04CH37579C).

7. Carpenter, D.D., Harding, T.S., Finelli, C.J., Montgomery, S.M. \& Passow, H.J. (2006). Engineering Students' Perceptions of and Attitudes Toward Cheating. Journal of Engineering Education, 95(3), 181-194.

8. McCabe, D.L. (1997). Classroom cheating among natural science and engineering majors. Science and Engineering Ethics. 3, 433-445.

9. Harding, T. S., Carpenter, D. D., Finelli, C. J., \& Passow, H. J. (2004). Does academic dishonesty relate to unethical behavior in professional practice? An exploratory study. Science and Engineering Ethics, 10, 311324.

10. Rest, J.R. (1979). Development in Judging Moral lssues. Minneapolis: University of Minnesota Press.

11. Rest, J.R., Narvaez, D., Bebeau, M., \& Thoma, S. J. (1999). Postconventional moral thinking: A neoKohlbergian approach. Mahwah, NJ: Lawrence Erlbaum Associates.

12. Mayhew, M. J., Hubbard, S. M., Finelli, C. J., Harding, T. S., and Carpenter, D. D. (2009, Summer). Using structural equation modeling to validate the theory of planned behavior as a model for predicting student cheating. Review of Higher Education, 32(4), 441-468.

13. Harding, T.S., Sutkus, J.A., Finelli, C.J., \& Carpenter, D.D. (2009). Engineering culture and the ethical development of undergraduate students. Presented at the annual meeting of the Research in Engineering Education Symposium: Palm Cove, Queensland, Australia

14. Miron, M. (1988). Students' evaluation and instructors' self-evaluation of university instruction. Higher Education, 17,175-181.

15. Nasser, F. \& Fresko, B. (2006). Predicting student ratings: The relationship between actual student ratings and instructors' predictions. Assessment and Evaluation in Higher Education, 31(1), 1-18.

16. Wachtel, H.K. (1998). Student evaluation of college teaching effectiveness: A brief review. Assessment and Evaluation in Higher Education, 23(2), 191-211.

17. Gill, D., Heins, M., \& Jones, P.B. (1984). Perceptions of medical school faculty members and students on clinical clerkship feedback. Journal of Medical Education, 59, 856-864.

18. MacLellan, E. (2001). Assessment for learning: The differing perceptions of tutors and students. Assessment and Evaluation in Higher Education, 26(4), 307-318.

19. Shannon, C. E. \& Weaver, W. (1949): A Transmission Model of Communication. Urbana, IL: University of Illinois Press

20. Fiske, John (1982). Introduction to Communication Studies. London: Routledge.

21. Ritchie, D. (1986). Shannon and Weaver: Unravelling the paradox of information. Communication Research,13, 278-298

22. Carnegie Foundation for the Advancement of Teaching (2009). The Carnegie Classifications of Institutions of Higher Education. Accessed at http://www.carnegiefoundation.org/classifications/ on 23 December, 2009.

23. Pieronek, C., Uhran, J., McWilliams, L., \& Silliman, S. "A demographic characterization of first-year engineering students," American Society for Engineering Education, 2006. 